\title{
Distribution and abundance of cultured scallop Patinopecten yessoensis in extensive sea beds as assessed by underwater camera
}

\author{
Seiji Goshima ${ }^{1}$, Hiroshi Fujiwara ${ }^{2}$ \\ ${ }^{1}$ Faculty of Fisheries, Hokkaido University, Minato-cho, Hakodate, Hokkaido 041, Japan \\ ${ }^{2}$ Tokoro Fishermen's Cooperative Association, Tokoro, Hokkaido 093-02, Japan
}

\begin{abstract}
A simple and precise system for population estimation of epi-megabenthos using an underwater photographic camera is proposed. A standard $35 \mathrm{~mm}$ film camera with motor wind mounted in an underwater case is attached on a stainless steel frame to photograph $1 \mathrm{~m}^{2}$ of sea bed. The camera is triggered by a rigid foot switch set off on contact with the sea bed; thus, only vertical lowering is needed in operation. Two-stage sampling was employed to estimate the extensively cultured Japanese scallop Patinopecten yessoensis; estimated densities were highly accurate and relative standard errors were within only 0.05 of the means. The estimated amount of harvest approximated closely the actual harvest. Precise density changes in a cohort, from seed release time to harvest, could be followed, providing essential information for fishery management of scallops. The distribution pattern of the population was analyzed. Contagious distribution patterns of the scallops were detected on a large scale, and they showed large areas of patchiness, but random distribution of individual scallops within the patches was observed on a small scale. Contagiousness decreased with age. Factors affecting the distribution pattern on large and small scales are discussed in relation to substrate types, current flow with subsequent downstream dispersal during swimming movements, and possible food depletion.
\end{abstract}

KEY WORDS: Scallop $\cdot$ Distribution $\cdot$ Population estimate $\cdot$ Underwater camera $\cdot$ Two-stage sampling

\section{INTRODUCTION}

Many megabenthic species living in soft sediment exhibit contagious distributional patterns, grouping together in large patches or beds. However, their spatial distribution tends to be more dispersed or random within patches (e.g. Jumars \& Eckman 1983, Schneider et al. 1987, Vezina 1988, Brand 1991). Many factors have been identified which may account for such distributional patterns (see Brand 1991 for review). Studies of these patches are important not only for basic ecological knowledge but also for fisheries management because fisheries for these species are concentrated on these patches (beds).

The sea ranching of scallop Patinopecten yessoensis has prospered along the coast of the Okhotsk Sea in Hokkaido, Japan. Every year, a known number of cultured young scallops ( 1 yr old) are released on a given fishing ground, providing a unique opportunity to study their distribution and population dynamics. Analysis of distribution patterns requires precise estimates of densities and localities that are also necessary in the management of this edible resource. Although there are several studies on distribution and population estimates of a number of scallop species (e.g. Olsen 1955, Caddy 1970, Vahl 1981, Langton \& Robinson 1990, Thouzeau et al. 1991, MacDonald \& Bajdik 1992), little work has been done on $P$, yessoensis (Fuji \& Kajihara 1977), the most common and exploited scallop species in Japan. This is mainly due to the lack of suitable methods for observation. Up to the present, the dredging method, which is dependent on gear efficiency, has been popular for population estimates in Hokkaido. However, as gear efficiency readily fluctuates (Dickie 1955, Caddy 1968, Fuji \& Kajihara 1977), estimates can vary considerably; thus, there is a need for more precise methods of measurement. 
The objectives of the present study were to develop an easier and more precise system for population estimates of epi-megabenthos using an underwater photographic camera, and to analyze the distribution patterns of scallops by the proposed census system. In addition, factors affecting the distribution patterns of the scallops are also discussed.

\section{MATERIALS AND METHODS}

Study area. The study was done in a subtidal fishery ground in Tokoro, Hokkaido, Japan $\left(44^{\circ} 13^{\prime} \mathrm{N}, 143^{\circ}\right.$ $55^{\prime}$ E) where extensive culture of scallops on the sea bed is carried out. The fishery ground was divided into 4 areas (Areas A to D), each being about $35 \mathrm{~km}^{2}$ and 20 to $65 \mathrm{~m}$ deep (Fig. 1). The sediments consisted mainly of coarse sand or pebbles (Nakagawa \& Wakui 1975).

Cuiture system. Spat of scallops are captured by collectors suspended in mid water in Lagoon Saroma, where spawning stock is preserved, in May or June when fully developed larvae are abundant (Maru 1985). The growing juveniles are suspended on floating lines in the lagoon until May or June of the following year when they attain 30 to $50 \mathrm{~mm}$ shell height. In May each year, about 350 million 1 yr old scallops are released in one of the 4 areas and allowed to grow for another $3 \mathrm{yr}(=4 \mathrm{yr}$ old $)$ until they attain a marketable size of about $120 \mathrm{~mm}$ shell height and $200 \mathrm{~g}$ wet wt. Before each release, the areas are first cleared of all megabenthos by dredging. Once the stock has been established on the sea bed, it can sustain exploitation on a 4 yr rotational basis. Thus, each area contains different age classes at a given time.

Underwater camera system. The camera system made for the present study by Ocean Research \& Sys-

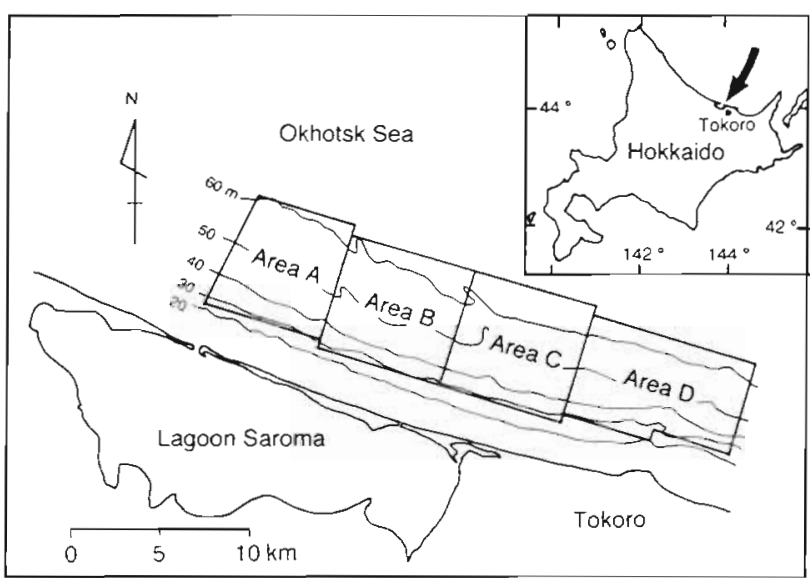

Fig. 1. Location of fishing areas (Areas $A$ to D) for scallops in Tokoro together with the bathymetry, and Lagoon Saroma where spawners are stocked

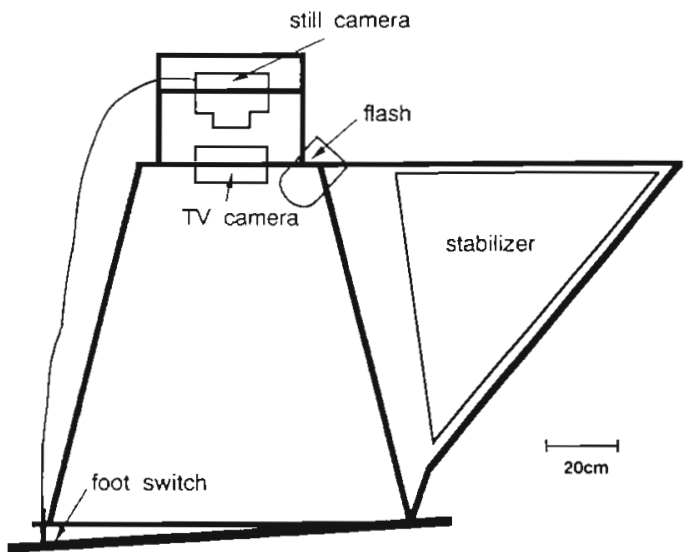

Fig. 2. Diagrammatic view of the underwater camera system used to photograph a $1 \mathrm{~m}^{2}$ section of sea bed. The camera is triggered by a rigid foot switch set off on contact with the sea bed

tems Co., Ltd, is illustrated in Fig. 2. The frame, made of stainless steel, is $1.1 \times 1.3$ (bottom) $\times 1.3 \mathrm{~m}$ high, and the entire equipment weighs about $50 \mathrm{~kg}$ in air. A standard $35 \mathrm{~mm}$ film camera with a motor wind mounted in an underwater case, and an electronic flash connected to the camera, are attached on top of the frame to photograph $1 \mathrm{~m}^{2}$ of sea bed. A vertical stabilizer made of sackcloth is attached to the side of the frame to prevent it from revolving when being lowered vertically underwater. The camera is fired by a rigid foot switch actuated on contact with the sea bed. Flashing could be detected on board through a TV monitor connected to a small underwater television camera (Q.I., Inc., model FM-1000) attached on the frame.

Counting of the individuals from the photographs (covering $1 \mathrm{~m}^{2}$ each) was made by divers with experience in observing scallops under natural conditions

Photo censuses. Each fishing ground (Areas A to D) was further divided into about 80 subareas measuring $1000 \times 500 \mathrm{~m}$. For each subarea, 5 to 10 pictures were taken randomly, totalling from 365 to 800 pictures per area. The photographed positions were estimated precisely by Global Positioning Systems (GPS). The photo censuses of the different age classes were taken in the 4 areas in 1992: twice for the 1 yr class in Area B, and once for the $2 \mathrm{yr}$ class in Area $C$, the 3 yr class in Area $A$, and the 4 yr class (just before harvesting) in Area D. In addition, densities of the $3 \mathrm{yr}$ class in Areas C, B \& D were estimated every August for 3 years (1989 to 1991) by the same method as in 1992 to compare successively the amount of harvest.

Data analyses. To analyze the distribution patterns within an area, the frequency of scallops in each $1 \mathrm{~m}^{2}$ was compared to the Poisson distribution, using a $\chi^{2}$ test, and then compared to the negative binomial dis- 
tribution by the Anscombe's T-test (Anscombe 1950). Aggregation patterns of individuals were analyzed using the $m^{*} / m$ index (Iwao 1968), where $m$ is mean population density, and $m$ ' is 'mean crowding' defined as the mean number of other individuals per individual in the same quadrat (Lloyd 1967). The value of $\mathrm{m} \% \mathrm{~m}$ is smaller than, equal to or larger than unity in uniform, random (Poisson), or clumped distribution, respectively.

Distribution patterns in subareas $(1000 \times 500 \mathrm{~m})$ within an area were analyzed by the regression of $m^{\text {* }}$ on $m$ for a series of subareas (Iwao 1968). Mean crowding is linearly related to mean density over a range of different densities, in which the intercept on the $m^{*}$ axis ( $\alpha$; an index of basic contagion) shows whether a unit of distribution is either an individual or a colony (an aggregation of individuals). The slope of the regression ( $\beta$; density-contagiousness coefficient) is equal to unity when the distribution of individuals or colonies follows the Poisson series, and larger and smaller than unity when the distribution is overdispersed and underdispersed, respectively (Iwao 1968, Iwao \& Kuno 1968, Kuno 1986).

To estimate population density, we employed the 2-stage sampling method proposed by Kuno (1976) in which biological information about the distribution of individuals among sampling units is incorporated into the well-known basic formula (e.g. Cochran 1963). This was done as the variance was smaller within subareas (within groups) but larger among subareas (among groups) (detailed description will be given in the section on distribution patterns). The first step was to select a sample of primary units (subareas within an area), and the second was to select a sample of elements (photographs within subareas) from each chosen primary unit. An area contains $L$ units, from which $I$ units were chosen. Every $l$ unit (subarea) contains the same number of $K$ elements, from which $k$ elements were chosen. The estimate of mean population density is given by

$$
\hat{m}=\frac{1}{l k} \sum_{i=1}^{1} \sum_{j=1}^{k} x_{i j}
$$

where $x_{i j}$ is the number of individuals found in the $j$ th element of the $i$ th unit. The variance of the mean density estimate is as follows:

$$
V(\hat{m})=\frac{1}{l}\left[\frac{1}{k}\left(1-\frac{k}{L}\right) V_{W}+\left(1-\frac{l}{L}\right) V_{B}\right]
$$

where

$$
V_{W}=(\alpha+1) m+\frac{\beta_{1}\left(\beta_{2}-1\right)}{\beta_{2}} m^{2}
$$

and

$$
V_{B}=\frac{\beta_{1}-\beta_{2}}{\beta_{2}} m^{2}
$$

in which $V_{W}$ and $V_{B}$ are intra- and inter-unit variances $\beta_{1}$ and $\beta_{2}$ are the values of the slope for the $m^{*}-m$ rela tions for the overall and the intra-units distributions, respectively, having the common intercept $\alpha$. Confidence intervals (CI) for estimated mean densities were calculated as

$$
\hat{m} \pm 1.96 \sqrt{V(\hat{m})}
$$

at $\mathrm{p}=0.95$. We used the relative standard errors $(D$, standard error of the mean / mean densityl as an index of precision level. The number of $k$ necessary for attaining a given precision level $(D)$, when the number of $l$ is fixed, is as follows:

$$
k_{D}=\frac{\frac{\alpha+1}{m}+\frac{\beta_{1}\left(\beta_{2}-1\right)}{\beta_{2}}}{1\left[D^{2}+\frac{1}{L}\left(\frac{\beta_{1}-\beta_{2}}{\beta_{2}}\right)\right]-\frac{\beta_{1}-\beta_{2}}{\beta_{2}}}
$$

Theoretical considerations and more detailed description of the 2-stage sampling method are given by Kuno (1976, 1986).

We estimated the necessary sample size (number of photographs) in each subarea using the above formula at $D=0.05$ which was smaller than the recommended value for life table analysis (Kuno 1986). We selected all the subareas as units in the area $(l=L)$ to avoid the trouble in selecting the subareas on board and to eliminate the large variance that might be present among the subareas.

To estimate the amount of harvest, we used $200 \mathrm{~g}$ as the mean wet wt for a scallop with shell, based on data from recent years' landings, $95 \%$ as survival rate from the time of density estimate (August before fishing year) to the time of harvest (next year), and $2000 \mathrm{t}$ as unharvested stock. These values were the same as those used for estimates by the dredge methods of the Tokoro Fishermen's Cooperative Association.

\section{RESULTS}

\section{Distribution patterns}

Fig. 3 shows the mean number per photograph (= mean no $\mathrm{m}^{-2}$ ) of the $3 \mathrm{yr}$ class scallops in each subarea in Area A in August 1992, 2 yr and 3 mo after release. The scallops showed contagious distribution pattern within the area, as indicated by long patches of higher densities from west to east in the central region, 

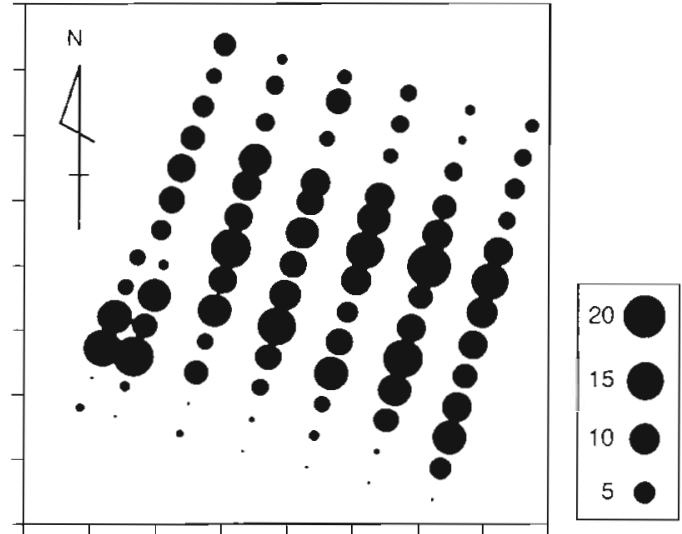

Fig. 3. Patinopecten yessoensis. Mean number of the 3 yr old class scallops per photograph ( $=$ mean no. $\left.\mathrm{m}^{-2}\right)$ in each subarea in Area $A$ in August 1992. One scale unit $=1 \mathrm{~km}$

despite the fact that nearly the same number of seed scallops ( 1 yr old) were sowed into every $\mathrm{km}^{2}$ mesh. The indices of contagiousness, $m \% m$, according to age within an area dre shown in Fig. 4. Aithough, the index decreases with age, the value at Age 4 is still above 1 (significant difference with Poisson distribution, $\mathrm{p}<$ $0.05)$ which indicates aggregated distribution even at an older age when they are ready for harvest. Fig. 5 shows the frequency per photograph (= frequency $\mathrm{m}^{-2}$ ) of 1 and 3 yr scallops in each area. The 1 yr old scallops (Fig. 5A) showed significant differences with Poisson distribution (random distribution) ( $p<0.05$ ), but not with negative binomial distribution (contagious distribution) ( $p>0.05)$. The 3 yr scallops showed only a negative binomial distribution $(p>0.05)$, although there was a decrease in the degree of contagiousness (Fig. 5B). The other age classes from every censuses also showed significant differences with Poisson $(\mathrm{p}<$ $0.05)$, but not with negative binomial distribution $(p>$ $0.05)$.

The regression of $m^{*}$ on $m$ for a series of subareas within an area of the most clumped scallops ( 1 yr old)

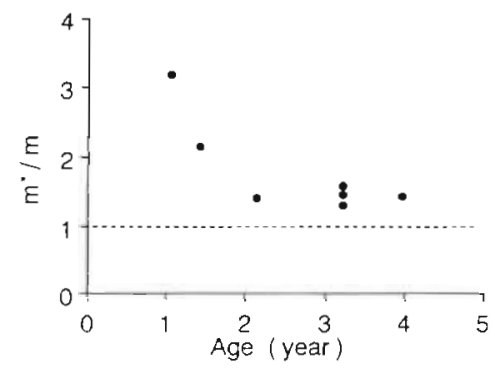

Fig. 4. Patinopecten yessoensis. Indices of contagiousness $(\mathrm{m} \% \mathrm{~m})$ according to age within an area. Horizontal dashed line shows the value of unity, indicating random distribution

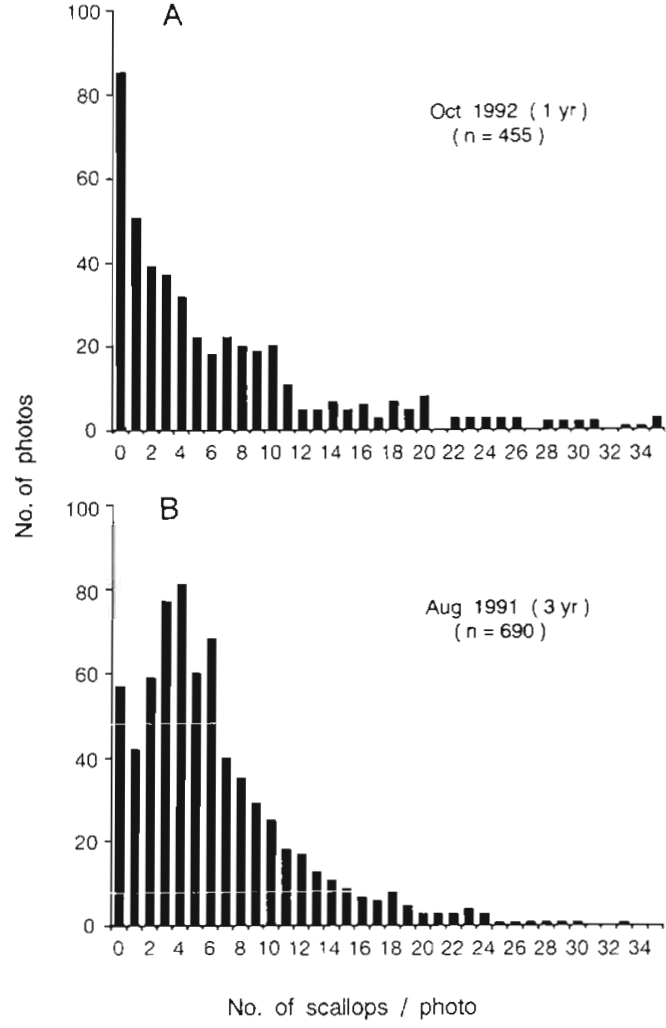

Fig. 5. Patinopecten yessoensis. Frequency per photograph ( = frequency $\mathrm{m}^{-2}$ ) of (A) 1 yr old and (B) 3 yr old scallops. Both (A) and (B) show a negative binomial distribution

and the least clumped scallops ( 3 yr old) is shown in Fig. 6A \& B. In both figures, the values of intercepts $(\alpha)$ are nearly zero $(p>0.05)$ and the values of slopes $(\beta)$ show no difference from unity $(p>0.05)$. The other age classes likewise showed the same trend, indicating that one unit of distribution is one individual and that the scallops were distributed randomly within the subareas.

\section{Estimate of necessary sample size}

We estimated the number of photographs $(k)$ necessary for various mean densities ( $m$, no. of scallops $\mathrm{m}^{-2}$ ) of the most clumped 1 yr old scallops, and the least clumped 3 yr old scallops, using Eq. (3) in which $l=L$ as follows:

$$
k=7.263 / m+0.452
$$

for the $1 \mathrm{vr}$ old, and

$$
k=5.797 / m+0.301
$$

for the 3 yr old scallops. These formulae show that as density decreases more photographs are needed. The 

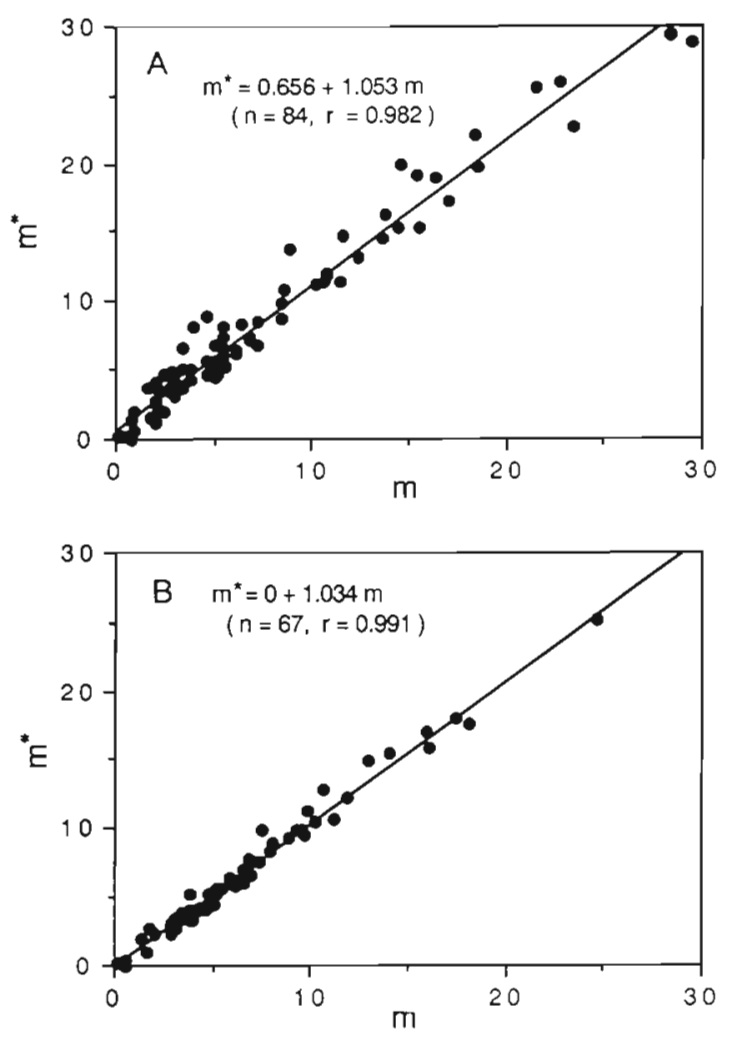

Fig. 6. Patinopecten yessoensis. Regression of mean crowding $\left(m^{*}\right)$ on mean density $(m)$ for a series of subareas within an area of (A) 1 yr old and (B) 3 yr old scallops

density of the 1 yr old group was about 7 to 12 scallops $\mathrm{m}^{-2}$ at the time of release (unpubl. data), so we needed at least 2 pictures in each subarea to estimate the mean density with an accuracy of $D=0.05$. For the 3 yr old group, as the variance decreased with time, the density also decreased due to mortality of 5 to 10 scallops $\mathrm{m}^{-2}$ (unpubl. data). In this case at least 1 or 2 pictures were needed at $D=0.05$ level. The other age classes also showed the same trend. It was, therefore, deemed sufficient to take 5 pictures for each subarea to estimate the mean density with an accuracy of $D=0.05$.

\section{Density estimate and fishing result}

Table 1 shows the results of the 2-stage sampling, carried out every August from 1989 to 1991, to estimate the mean densities of the $3 \mathrm{yr}$ old scallops and the amount harvested the next fishing season (4 yr old). Density estimates were highly accurate, and relative standard errors were within 0.05 and the values at $95 \% \mathrm{CI}$ within 0.1 of the estimated means, respectively. Density in Area $C$ was $5.75 \pm 0.20 \mathrm{~m}^{-2}$ at $95 \%$ CI. The estimated stock was $2.10 \times 10^{8}$ and the estimated harvest was $37900 \mathrm{t}$. This value was close to the actual landing of $38600 \mathrm{t}$ in Area $\mathrm{C}$ in 1990. In Area B, the estimated fishable amount was $51100 \mathrm{t}$ in August 1990 while the actual harvest was only $24700 \mathrm{t}$ in 1991. In Area $D$, the estimated mean density was $6.32 \pm 0.21$ $\mathrm{m}^{-2}$ in August 1991 and $6.09 \pm 0.31 \mathrm{~m}^{-2}$ in May 1992. May 1992 was the period prior to harvest in which one could not detect any density change. The actual harvest in this area in 1992 was $40800 t$, very close to the $40000 \mathrm{t}$ estimate.

\section{DISCUSSION}

\section{Comparison of methods for population estimates}

There are several methods employed for the estimate of population density of epi-megafauna including scallops: (1) the dredge method using gear efficiency (e.g. Dickie 1955, Fuji \& Kajihara 1977); (2) direct counts or photographic camera by diving (e.g. Olsen

Table 1. Patinopecten yessoensis. Estimation of mean density $( \pm 95 \% \mathrm{CI}$ ) and fishing amount by 2 -stage yearly sampling of scallop by the photo census

\begin{tabular}{|c|c|c|c|c|}
\hline & \multicolumn{4}{|c|}{ Area } \\
\hline & $\mathrm{C}$ & $\mathrm{B}$ & $\mathrm{D}$ & $\mathrm{D}$ \\
\hline Census date & August 1989 & August 1990 & August 1991 & May 1992 \\
\hline Area $\left(\mathrm{km}^{2}\right)$ & 36.5 & 35.0 & 34.5 & 34.5 \\
\hline Density (ind. $\mathrm{m}^{-2}$ ) & $5.751 \pm 0.203$ & $7.990 \pm 0.230$ & $6.315 \pm 0.206$ & $6.090 \pm 0.307$ \\
\hline $\begin{array}{l}\text { No. of scallops } \\
\text { (range) }\end{array}$ & $\begin{array}{c}2.10 \times 10^{8} \\
\left(2.03-2.17 \times 10^{8}\right)\end{array}$ & $\begin{array}{c}2.80 \times 10^{8} \\
\left(2.72-2.88 \times 10^{8}\right)\end{array}$ & $\begin{array}{c}2.18 \times 10^{8} \\
\left(2.11-2.25 \times 10^{8}\right)\end{array}$ & $\begin{array}{c}2.10 \times 10^{8} \\
\left(2.00-2.21 \times 10^{8}\right)\end{array}$ \\
\hline Estimated stock $(\mathrm{t})$ & 39883 & 53134 & 41395 & 42021 \\
\hline $\begin{array}{l}\text { Est. of fishing amount (t) } \\
\text { (range) }\end{array}$ & $\begin{array}{c}37883 \\
(36475-39291)\end{array}$ & $\begin{array}{c}51134 \\
(49604-52663)\end{array}$ & $\begin{array}{c}39395 \\
(38044-40745)\end{array}$ & $\begin{array}{c}40021 \\
(37903-42139)\end{array}$ \\
\hline Fishing amount (t) & 38624 & 24723 & 40784 & 40784 \\
\hline
\end{tabular}


1955. Caddy 1968) or from a manned submersible (e.g. Caddy 1970, Fuji \& Kajihara 1977, Langton \& Robinson 1990); and (3) remotely-operated underwater TV (e.g. Holme \& Barrett 1977, Franklin et al. 1980) or photographic camera (e.g. MaIntyre 1956. Caddy 1970, Fujita \& Ohta 1990). In the dredge method, a consistent sampling efficiency could not be achieved for population estimates; the gear efficiency tends to fluctuate depending on such biological, environmental and operating conditions as body size of the benthic animals, sediment characteristics, weather, depth, and towing speed (Dickie 1955, Fuji \& Kajihara 1977). In addition, it consumes much time and needs many workers.

The diving method produces an actual count of epimegabenthos, but has time limitations imposed by the amount of air carried by a diver, and physical factors such as depth: some scallops inhabit depths down to $65 \mathrm{~m}$ which is below usual diving depths, and temperature limits efficiency (Gamble 1984). Direct visual inspection is possible using a manned submersible, but the motor unit is expensive, needs a skilled operator and is somewhat risky. Television systems have the advantage of providing a continuous and instantaneous view. Their limitations are poorer definition than still photography, and expensive and complex equipment (Franklin et al. 1980, Holme 1984). In the present case, the estimated mean density of the scallops was high -10 scallops $\mathrm{m}^{-2}$, reaching a maximum of $35 \mathrm{~m}^{-2}$ (Figs. $5 \& 6$ ). This value is 5 to 10 times higher than the usual densities of wild scallops (see Orensanz et al. 1991). Therefore, counting of scallops might be difficult on video tapes with poor image quality, resulting in a drop in efficiency during continuous counting (Franklin et al. 1980).

On the other hand, quality photographs could provide a clear image of the sea bed. The present photographic system has the advantage of being simple in structure, which means less expense and less care necessary in operation and maintenance; the photographic and monitor video cameras and the underwater camera case are all standard production models in which only vertical lowering is needed and, therefore, operation time is shorter than that of any other method. The present photo census in an area needed only $2 \mathrm{~d}$ and 4 people during the field work, and an additional $2 \mathrm{~d}$ for counting the scallops. Clear photographs and precise estimates of localities by GPS employing the 2-stage sampling system surely provide a highly accurate estimate of the population.

Our estimates at $95 \% \mathrm{Cl}$ were within $10 \%$ of the estimated means (Table 1). Using these values, we were also able to estimate precisely the expected yearly harvest, except in 1991 when the total catch was half of the estimated one (Table 1). Between August
1990 (stock estimate time) and June 1991 (harvest time), the scallops suffered high mortality and the survivors showed loss in body weight due to unknown cause(s) (unpubl. data). Such discrepancies are inevitable in time-span studies but do not occur as a result of the sampling methodology employed.

\section{Distribution patterns}

A clustered distribution on a large scale is probably typical of megabenthos including scallops (see Brand 1991 for review). Many factors affecting spatial distribution have been given, such as depth, substrate type (Caddy 1970, Schneider et al. 1987. Thouzeau et al. 1991), food availability, water currents (Olsen 1955. Thouzeau et al. 1991), and predation (Langton \& Robinson 1990). We detected contagious distribution patterns of the scallops within the fishing grounds on a large scale (in the order of a few $\mathrm{km}^{2}$ ) (Figs. 3,4 \& 5). The low density area was on the landward side, which consisted mainly of fine sand sediment (Nakagawa \& Wakui 1975, authors' unpubl. data). There are many studies showing that higher density areas of the scallop species are in gravel and coarse sand sediment rather than in muddy or fine sand areas (Caddy 1970, Schneider et al. 1987. Thouzeau et al. 1991). Coarse grain sediment types have been generally associated with relatively strong current flow (Brand 1991) that provides favorable food conditions for the scallops. Abundant food supply keeps the scallop beds at a higher density, although feeding and growth inhibitions at very high rates of flow have also been reported (Wildish et al. 1987). However, the observed low density area on the seaward side where sediment is composed of rather coarse grain (unpubl. data) could not be explained at present.

Some scallop beds were long and narrow with the long axis parallel to the current flow (Olsen 1955. Thouzeau et al. 1991), which might be explained by the concentration of larvae settling out in regions just inside or just away from areas of strong current flow and subsequent downstream dispersal during swimming movements (Brand 1991). A flow from the northwest to the southeast generally prevails along the coast of Tokoro (Aota 1975), which may cause downstream dispersal after release, possibly explaining the observed long patches (Fig. 3).

Young wild scallops are less dispersed (Fuji \& Kajihara 1977. Thouzeau et al. 1991) and our results show that contagiousness decreased with age (Fig. 4). However, we do not discount the possibility that the aggregated distribution of the 1 yr old group might have been partially caused by uneven releases despite efforts to put the same number of seedlings in every 
$\mathrm{km}^{2}$ mesh. Subsequent emigration from an unsuitable area, early stage mortality (Hayashi et al. 1976), and dispersion by current flow due to more active swimming movements in younger scallops than in older ones (Caddy 1968) could likewise account for this decreasing tendency,

In contrast to the large-scale contagious distribution pattern, random (Poisson) distributions were also observed on a small scale (within subareas, in the order of $0.5 \mathrm{~km}^{2}$ ) (Fig. 6). This random distribution within the beds has been shown in several cases (Thouzeau et al. 1991, MacDonald \& Bajdik 1992), although aggregated distribution has also been observed in other cases (Caddy 1970, Fuji \& Kajihara 1977, Vahl 1981, MacDonald \& Thompson 1986, Langton \& Robinson 1990, MacDonald \& Bajdik 1992). MacDonald \& Bajdik (1992) have suggested that suspension depletion just above the sea bed affects the small scale distribution pattern of Placopecten magellanicus, that is, from the aggregated type to random or uniform pattern. Since the present population exhibits higher densities than the wild ones (see Brand 1991 and Orensanz et al. 1991 for review), such food depletion could also be considered. However, there is little information available on the scale on which seston depletion may be operating (Peterson \& Black 1987, MacDonald \& Bajdik 1992).

Acknowledgements. We are grateful to $\mathrm{T}$ Ogasawara and other members of the Tokoro Fishermen's Cooperative Association for providing the facilities. H. Sumita and Y Takahashi, Ocean Research \& Systems, Co. Ltd., are acknowledged for their close cooperation in developing the underwater photographic equipment. We thank A. Fuji, S. Nakao, R. U. Gamboa, E. T. Quinitio and an anonymous reviewer for comments that improved this paper. This study was partially supported by a grant from Hokusui Kyokai (S.G.).

\section{LITERATURE CITED}

Anscombe, F. J. (1950). Sampling theory of the negative binomial and logarithmic series distributions. Biometrika 37 : $358-382$

Aota, M. (1975). Studies on the Soya warm current. Low Temp. Sci. Ser. A. 33: 151-172 (in Japanese, English summary)

Brand, A. R. (1991). Scallop ecology: distribution and behaviour. In: Shumway, S. E. (ed.) Scallops: biology, ecology and aquaculture. Elsevier, Amsterdam, p. 517-584

Caddy, J. F. (1968). Underwater observations on scallop (Placopecten magellanicus) behaviour and drag efficiency. J. Fish. Res. Bd Can. 25: 2123-2141

Caddy, J. F. (1970). A method of surveying scallop populations from a submersible. J. Fish. Res. Bd Can. 27: 535-549

Cochran, W. G. (1963). Sampling techniques, 2nd edn. John Wiley \& Sons, New York

Dickie, L. M. (1955). Fluctuations in abundance of the giant scallop, Placopecten magellanicus (Gmelin), in the Digby area of the Bay of Fundy. J. Fish. Res. Bd Can. 12: 797-857

Franklin, A., Pickett, G. D., Holme, N. A., Barrett, R. L. (1980). Surveying stocks of scallops (Pecten maximus) and queens (Chlamys opercularis) with underwater television. J. mar. biol. Ass. U.K. 60: 181-191

Fuji, A., Kajihara, M. (1977). Quantitative surveys of megalobenthos from submersibles. In: Japan. Soc. Sci. Fish. (ed.) Marine ecology and measuring. Koseisha Koseikaku, Tokyo, p. 67-82 (in Japanese)

Fujita, T. Ohta, S. (1990). Size structure of dense populations of the brittle star Ophiura sarsii (Ophiuroidea: Echinodermata) in the bathyal zone around Japan. Mar. Ecol. Prog Ser. 64: $113-122$

Gamble, J. C. (1984). Diving. In: Holme, N. A., McIntyre, A. D (eds.) Methods for the study of marine benthos. Blackwell Oxford, p. 99-139

Hayashi, T., Tomita, K., Wakui, T., Ito, H., Matsuya, M. (1976) Propagation of scallop by transplantation of seed in the Okhotsk Sea coast of northern Hokkaido. Month. J. Fish. Exp. Sta. Hokkaido 33: 1-16 (in Japanese)

Holme, N. A. (1984). Photography and television. In: Holme N. A., McIntyre, A. D. (eds.) Methods for the study of marine benthos. Blackwell, Oxford, p. 66-98

Holme, N. A., Barrett, R. L. (1977). A sledge with television and photographic cameras for quantitative investigation of the epifauna on the continental shelf. J. mar. biol. Ass. U.K. 57: 391-403

Iwao, S. (1968). A new regression method for analyzing the aggregation pattern of animal populations. Res. Pop. Ecol. 10: $1-20$

Iwao, S., Kuno, E. (1968). Use of the regression of mean crowding on mean density for estimating sample size and the transformation of data for the analysis of variance. Res. Pop. Ecol. 10: 210-214

Jumars, P. A., Eckman, J. E. (1983). Spatial structure within deep-sea benthic communities. In: Rowe, G. T. (ed.) Deep-sea biology. John Wiley and Sons, New York, p. $399-451$

Kuno, E. (1976). Multi-stage sampling for population estimation. Res. Pop. Ecol. 18: 39-56

Kuno, E. (1986). Methods for studies on population dynamics. I. Estimates of population size. Kyoritsu Shuppan, Tokyo (in Japanese)

Langton, R. W., Robinson, W. E. (1990). Faunal associations on scallop grounds in the western Gulf of Maine. J. exp. mar. Biol. Ecol. 144: 157-171

Lloyd, M. (1967). 'Mean crowding'. J. Anim. Ecol. 36: 1-30

MacDonald, B. A., Bajdik, C. D. (1992). Orientation and distribution of individual Placopecten magellanicus (Gmelin) in two natural populations with differing production. Can. J. Fish. Aquat. Sci. 49: 2086-2092

MacDonald, B. A., Thompson, R. J. (1986). Production, dynamics and energy partitioning in two populations of the giant scallop placopecten magellanicus (Gmelin). J. exp. mar. Biol. Ecol. 101: 285-299

Maru, K. (1985). Ecological studies on the seed production of scallop, Patinopecten yessoensis (Jay). J. Fish. Exp. Sta. Hokkaido 27: 1-53 (in Japanese, English abstract)

McIntyre, A. D. (1956). The use of trawl, grab and camera in estimating benthos. J. mar. biol. Ass. U.K. 35: 419-429

Nakagawa, Y, Wakui, T. (1975). The bottom sediments and macrobenthos in the scallop fishing ground in Tokoro, Hokkaido. Month. J. Fish. Exp. Sta. Hokkaido 32: 16-30 (in Japanese)

Olsen, A. M. (1955). Underwater studies on the Tasmanian commercial scallop, Notovola meridionalis (Tate) (Lamel- 
libranchiata: Pectinidae). Aust. J. mar. Freshwat. Res. 6: $392-409$

Orensanz, J. M., Parma, A. M., Iribarne, O. O. (1991). Population dynamics and management of natural stocks. In: Shumway, S. E. (ed.) Scallops: biology, ecology and aquaculture. Elsevier, Amsterdam, 625-713

Peterson, C. H., Black, R. (1987). Resource depletion by active suspension feeders on tidal flats: influence of local density and tidal elevation. Limnol. Oceanogr. 32: 143-166

Schneider, D. C., Gagnon, J. M., Gilkinson, K. D. (1987). Patchiness of epibenthic megafauna on the outer Grand Banks of Newfoundland. Mar. Ecol. Prog. Ser. 39: 1-13

Thouzeau, G., Robert, G., Smith, S. J. (1991). Spatial variability in distribution and growth of juvenile and adult sea

This article was submitted to the editor scallops Placopecten magellanicus (Gmelin) on eastern Georges Bank (Northwest Atlantic). Mar. Ecol. Prog. Ser. 74: 205-218

Vahl, O. (1981). Energy transformations by the Iceland scallop, Chlamys islandica (O.F. Müller), from $70^{\circ} \mathrm{N}$. II. The population energy budget. J. exp. mar. Biol. Ecol. 53: $297-303$

Vezina, A. F. (1988). Sampling variance and the design of quantitative surveys of marine benthos. Mar. Biol. 97: $151-155$

Wildish, D. J., Kristmanson, D. D., Hoar, R. L., DeCoste, A. M., McCormick, S. D., White, A. W. (1987). Giant scallop feeding and growth responses to flow. J. exp. mar. Biol. Ecol. 113: $207-220$

Manuscript first received: December 14, 1993

Revised version accepted: April 27, 1994 